\title{
Association between the perceived environment and physical activity among adults in Latin America: a systematic review
}

\author{
Carlos M Arango ${ }^{1,2^{*}}$, Diana C Páez ${ }^{1}$, Rodrigo S Reis ${ }^{3,4}$, Ross C Brownson ${ }^{1,5}$ and Diana C Parra ${ }^{1}$
}

\begin{abstract}
Background: Activity friendly environments have been identified as promising strategies to increase physical activity levels in the population. Associations between perceived environmental attributes and physical activity in Latin America may vary from those observed in high income countries. The objective of this systematic review is to identify which perceived environmental attributes are associated with physical activity in Latin America.

Methods: Systematic literature search of articles published in English, Portuguese, and Spanish in four databases was conducted (PubMed, Virtual Health Library, EBSCO, and Web of Science). Associations with environmental attributes were analyzed separately for physical activity domains. Fifteen articles were included in the analysis.

Results: All studies had cross-sectional designs. The majority of associations were statistically non-significant, and only four associations were found in the unexpected direction. Leisure-time and transport-related physical activity were the domains most frequently included in the studies and had higher number of associations in the expected direction. Leisure-time physical activity showed a convincing association in the expected direction with safety during the day. Transport-related physical activity had a convincing association with presence of street lighting.

Conclusions: This study shows that perceived environmental attributes and their relationship with physical activity appears to be domain, and context specific. In addition, findings from this study show inconsistencies with the information gathered from high-income countries.
\end{abstract}

Keywords: Environment, Exercise, Review, Public health, Leisure, Transportation

\section{Background}

Rapid urbanization in Latin America has been one of the contributors of an increased burden of non-communicable diseases (NCDs) [1]. Changes in modes of daily transportation [2] with a major shift from public to individual means (e.g. cars) have also been documented [3]. Both of these trends have played a role in the increasing prevalence of physical inactivity in the region [4]. Studies focusing exclusively on sedentary behavior in Latin America have not been completed. However, a paper by Hallal et al. published on the recent Lancet series on physical activity reported that the overall prevalence of physical inactivity among

\footnotetext{
*Correspondence: carangopaternina@go.wustl.edu

${ }^{1}$ Prevention Research Center in St. Louis, Brown School, Washington University in St. Louis, 660 S. Euclid Ave, St. Louis, Missouri MO 63110, USA ${ }^{2}$ Department of Health, Leisure and Exercise Science, University of West Florida, 11000 University Parkway, 32514, Pensacola, Florida, USA Full list of author information is available at the end of the article
}

adults in the Americas was 43.2\% [4]. Data from Latin America was limited to Colombia, Ecuador, Brazil, Uruguay, Argentina and Paraguay.

Activity friendly environments have been identified as promising strategies to increase physical activity levels in the population [5-7]. Such understanding is based on evidence from systematic reviews and observational studies looking at the association between perceived environmental features (i.e. presence of sidewalks, proximity to parks, destinations and accessibility etc.) and likelihood of physical activity (e.g. walking for transport or leisure time) [8]. Although the majority of the studies on this topic have a cross-sectional design, previous systematic reviews have found that associations are fairly consistent and show that perceived traffic safety, neighborhood aesthetics, convenience of facilities for walking, accessibility of destinations [9], street scale strategies (relighting of streets, redesigning of streets, and

\section{Biomed Central}

(c) 2013 Arango et al.; licensee BioMed Central Ltd. This is an open access article distributed under the terms of the Creative Commons Attribution License (http://creativecommons.org/licenses/by/2.0), which permits unrestricted use, distribution, and reproduction in any medium, provided the original work is properly cited. 
improvements in street aesthetics) [7] are associated with higher physical activity. The limited evidence from lowincome and middle-income countries (most of them from upper-middle income) indicates that perceived access to recreation facilities, density of exercise facilities and urbanization are positively associated with physical activity [10]. While association between safety (e.g. crime and traffic) and physical activity are less consistent [10].

Nonetheless, most of the evidence on this issue has been generated in high-income countries [10], thus limiting the generalizability of the findings [11] to other regions with stark differences in urban and social environments such as Latin America [12]. Latin America has one of the highest urbanization rates in the world with $80 \%$ of the population living in urban centers [3]. Taking into account this context, associations between perceived environmental attributes and physical activity may vary from those observed in high income countries $[11,13,14]$. For instance, Latin American cities are characterized by high land-mix use as well as higher density and connectivity [15-17]; these attributes have commonly been found to be associated with physical activity [18]. In addition, there are socio-economic inequalities, cultural aspects, and other contextual differences in the environment (crime rates unsafe, poor access to PA facilities and public transportation predominantly made by busses) unique to low and middle-income countries such as those found in Latin America, where physical activity is partially taken on a utilitarian instead of a recreational purpose. In this sense, people engage in high levels of transportation related physical activity versus leisure time.

Therefore, the objective of this systematic review was to identify which perceived environmental attributes are associated with physical activity in Latin America. Findings from this study could provide useful insights for decision makers and practitioners in order to prioritize limited resources, and have the best chance of success $[19,20]$.

\section{Methods}

\section{Search strategy}

The following electronic databases were searched for entries between 1990 to August 6th 2012: PubMed, Virtual Health Library (which includes LILACS, MEDLINE, MEDCARIB, OPAS/OMS, PAHO, WHOLIS, and SCIELO); EBSCO, and Web of Science. The search was limited to articles published in English, Portuguese, and Spanish (the languages officially spoken in the region). Relevant publications were identified using the following keywords: urban landscape, streetscape, urban form, urban design, environmental design, walkability, perception of the environment, or perceived environment, physical activity, exercise, physical inactivity, walking, cycling, bicycle use, walk, bike, active transport, motor activity, or pedestrian. This systematic review was focused on perceived environment, a cognitive process; objective measures of the environment were not explore due to lack of information. Figure 1 presents the flow chart of the systematic literature search, as suggested by the PRISMA guidelines [21].

\section{Study selection}

One author screened titles and abstracts to determine whether the articles were eligible for full article review. Studies that met the following criteria were selected for abstraction: 1) examined physical activity as an outcome; 2) were original research studies; 3 ) were conducted only among adults or older adults; 4) compared outcomes between groups of participants in the analysis according to stratifying variables (example, low/poor vs. high/good perception); 5) perceived attributes of the environment were examined in detail; and 6) were conducted in a country from Latin America. We excluded studies conducted in adolescents because correlates of physical activity and perceptions related to the environment may have substantial differences between adolescents and adults [10]. The classification of geographic regions employed by the United Nations was used to identify countries located in the Latin America region [22]. A similar approach has been used in previous studies allowing comparisons among geographic regions [10]. A backward search was conducted using the reference lists of the selected papers, this yield two additional papers that were included in the analysis.

\section{Data extraction}

Information abstracted included study's authors, publication year, age range of the subjects, country and city where the study was conducted, study design, sample size, details of perceived environment physical activity measurements, and measurement of association. Perceived environment variables were categorized largely based on the categories presented in the Neighborhood Environment Walkability Scale (NEWS) [23,24], which is a scale created to evaluate perceptions of community environment related with physical activity. The NEWS and its abbreviated version (A-NEWS), has been frequently used in studies conducted in the United States [25,26], Europe [27], Australia [28], Japan [29], and Latin America $[13,30]$. Therefore, its categories are comparable across different regions. The following categories were used: access to services and shops, access to recreational facilities, walking/cycling facilities and maintenance, street design, aesthetics, personal and crime related safety, and traffic related safety. Physical activity domains were categorized as total physical activity, leisure-time, transport-related, and total walking (including walking for any purpose).

Relationships between perceived environment attributes and physical activity domains were interpreted in terms of whether they occurred in the expected direction 


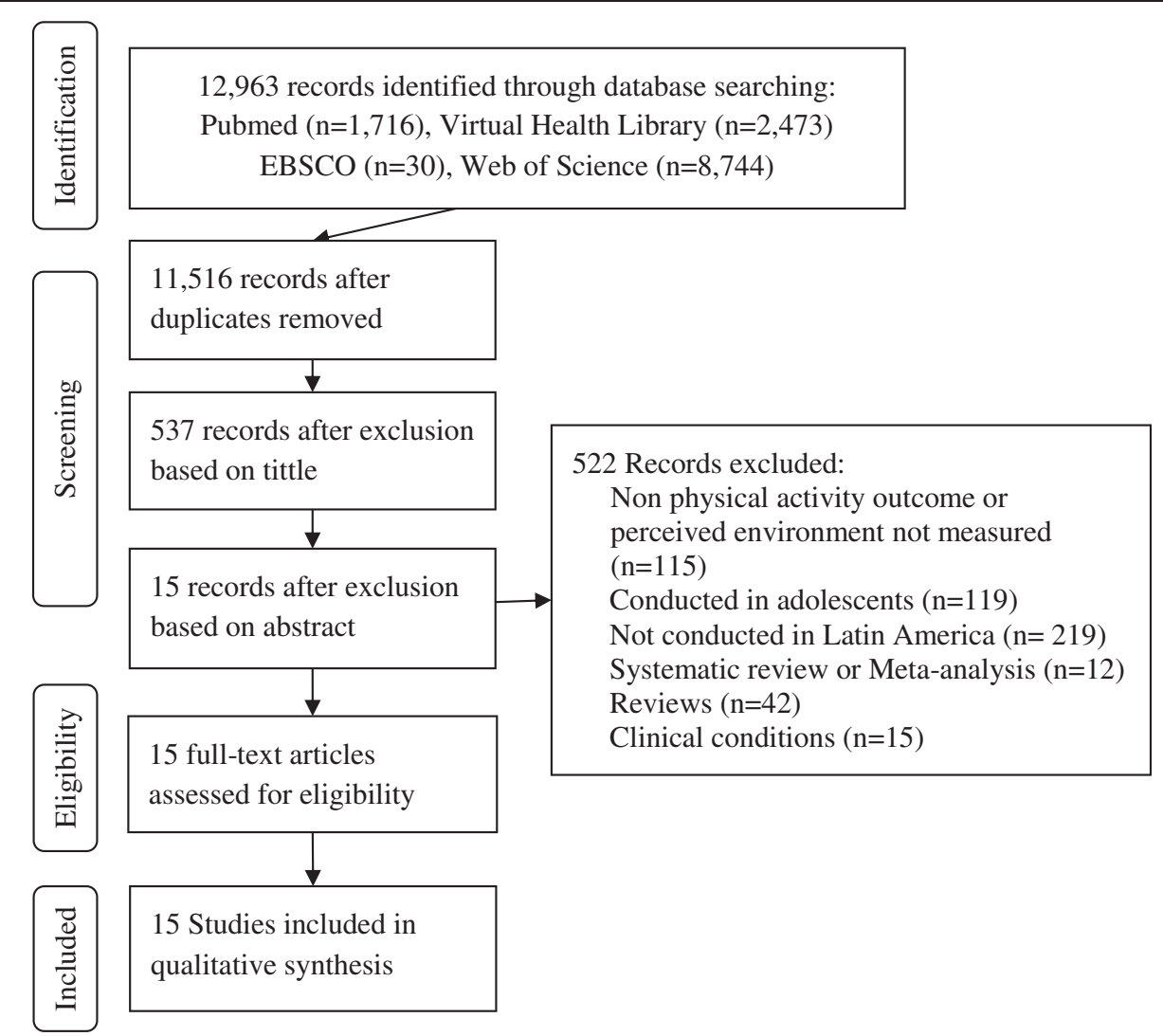

Figure 1 Flow chart of the systematic literature search on perceived environment attributes and physical activity in Latin America.

(e.g. good perception of safety associated with meeting the physical activity recommendation), the unexpected direction (e.g. perception of garbage accumulation associated with meeting the physical activity recommendation), or had no statistical association based on the significance level reported in each study $(\mathrm{p}<0.05)$. Because some of the selected papers reported stratified results, a publication could be counted and included more than once, resulting in multiple measures of association that could report different directions of association (i.e. positive for men and negative for women).

Finally, results were classified into four categories following an approach used in similar studies [10,31,32]. A finding was classified as "convincing" if two-thirds (66\%) or more of the reported associations on a specific environmental attribute were found to be in the same direction. A "suggestive association" was registered if equal number of results showed non-significant and significant associations; in cases where the same number of associations in the unexpected and expected directions where reported, were classified as "contradictory results". Finally "non-significant association" was used to describe findings where more than two-thirds $(66 \%)$ of the associations reported on a specific environmental attribute were not statistically significant. In addition, to ensure consistency across the results only associations from at least three studies, conducted in different populations were used as a basis for classification of an association. Because not all potential associations between perceived environment attributes and physical activity have been studied, those cases were coded as "associations not studied".

\section{Assessing study quality}

To assess the methodological quality of the selected articles, the STROBE checklist (The Strengthening the Reporting of Observational Studies in Epidemiology) [33] was adapted according to the aim and characteristics of this study. The final checklist included 24 items that assess the quality of the study design, results, and discussion according to the reported information. Each item scored one point if full reporting was met, or zero if not or partially reported. Two independent raters conducted the scoring and disagreements were conciliated by a third reviewer. Data abstraction, classification, and quality assessment of each study were independently conducted by two authors. Any discrepancies were solved by a third reviewer.

\section{Results}

The electronic search yielded 12,963 articles from the selected databases (Pubmed, $\mathrm{n}=1,716$; Virtual Health 
Library, $\mathrm{n}=2473$; EBSCO, $\mathrm{n}=30$; Web of Science, $\mathrm{n}=$ 8744). After title screening, 537 abstracts were reviewed applying the inclusion criteria. Of excluded studies, 115 did not have a physical activity outcome or did not include perceived environment 219 were not conducted in Latin America, 54 were not original research studies (12 systematic reviews or meta-analysis, and 42 reviews), 15 were conducted in populations with clinical conditions, and 119 focused only on adolescents. Finally, 15 studies were included to undergo full abstraction (Figure 1).

\section{Descriptive review}

Table 1 presents results from the descriptive characteristics of the abstracted studies $[11,13,14,30,34-44]$. Full- texts of the articles were available in different languages, three in Portuguese, two in Spanish, and ten in English. All of them were cross-sectional studies. Twelve studies were conducted in Brazil [11,13,30,34-39,41,43,44] and three in Colombia $[14,40,42]$. Six out of the fifteen studies were exclusively focused on older adult population (60 years and older), the remaining studied included individuals 16 years and older (Table 1). The vast majority of the studies used the NEWS (73\%), and the IPAQ long version (International Physical Activity Questionnaire) [45] (86\%) as tools to measure perceived environment and physical activity, respectively. Leisure-time physical activity was the most frequent domain studied (60\%), followed by transport-related (53\%), total walking (40\%), and total physical activity (13\%).

Table 1 Selected characteristics of publications included in the systematic review on perceived environment attributes and physical activity in Latin America

\begin{tabular}{|c|c|c|c|c|c|c|c|c|c|}
\hline \multirow{3}{*}{$\begin{array}{l}\text { Author; year } \\
\text { (ID) }\end{array}$} & \multicolumn{3}{|c|}{ Sample } & \multicolumn{3}{|c|}{ Measurement } & \multicolumn{3}{|c|}{$\begin{array}{c}\text { Quality assessment } \\
\text { (STROBE) }\end{array}$} \\
\hline & $\mathbf{N}$ & Country (city) & $\begin{array}{c}\mathrm{PE} \\
\text { Instrument }\end{array}$ & $\begin{array}{c}\mathrm{PA} \\
\text { Instrument }\end{array}$ & PA Domains & Methods & Results & Discussion & $\begin{array}{l}\text { Score } \\
\text { total }\end{array}$ \\
\hline & (Age range) & & & & & (of 15) & (of 5) & (of 4) & (of 24) \\
\hline $\begin{array}{l}\text { Amorim et al. } \\
\text { [38] } 2010 \text { (1) }\end{array}$ & $972(20-69)$ & Brazil (Pelotas) & NEWS & IPAQ L-V & LTPA, TRPA & 11 & 4 & 3 & 18 \\
\hline $\begin{array}{l}\text { Corseuil et al. } \\
\text { [34] } 2011 \text { (2) }\end{array}$ & $1652(60+)$ & Brazil (Florianopolis) & NEWS & IPAQ L-V & TRPA & 10 & 4 & 2 & 16 \\
\hline $\begin{array}{l}\text { Florindo et al. } \\
\text { [30] } 2011 \text { (3) }\end{array}$ & $890(18+)$ & Brazil (Ermelino Matarazzo) & NEWS & IPAQ L-V & LTPA, TRPA & 11 & 3 & 3 & 17 \\
\hline $\begin{array}{l}\text { Gomes et al. } \\
\text { [13] } 2011 \text { (4) }\end{array}$ & $6166(16+)$ & $\begin{array}{c}\text { Brazil (Curitiba, } \\
\text { Recife, and Vitoria) }\end{array}$ & NEWS & IPAQ L-V & TotalW & 11 & 5 & 3 & 19 \\
\hline $\begin{array}{l}\text { Gómez et al. } \\
\text { [14] } 2010 \text { (5) }\end{array}$ & $1966(60+)$ & Colombia (Bogotá) & Questions & IPAQ L-V & TotalW & 11 & 3 & 3 & 17 \\
\hline $\begin{array}{l}\text { Hallal et al. } \\
\text { [39] } 2010 \text { (6) }\end{array}$ & $2046(16+)$ & Brazil (Recife) & NEWS & IPAQ L-V & $\begin{array}{l}\text { LTPA, TRPA, } \\
\text { TotalW }\end{array}$ & 11 & 4 & 3 & 18 \\
\hline $\begin{array}{l}\text { Herazo-Beltrán } \\
\text { et al. } \\
\text { [40] } 2010 \text { (7) }\end{array}$ & $350(18-65)$ & Colombia (Cartagena) & IPS-EM & $\begin{array}{l}\text { IPAQ Short } \\
\text { version }\end{array}$ & TotalPA & 10 & 4 & 3 & 17 \\
\hline $\begin{array}{l}\text { Parra et al. } \\
\text { [11] } 2011 \text { (8) }\end{array}$ & $2008(18+)$ & Brazil (Curitiba) & NEWS & IPAQ L-V & $\begin{array}{l}\text { TotalPA, LTPA, } \\
\text { TRPA, TotalW }\end{array}$ & 8 & 3 & 3 & 14 \\
\hline $\begin{array}{l}\text { Salvador et al. } \\
\text { [35] } 2009 \text { (9) }\end{array}$ & $385(60+)$ & Brazil (Ermelino Matarazzo) & NEWS & IPAQ L-V & LTPA & 12 & 5 & 3 & 20 \\
\hline $\begin{array}{l}\text { Salvador et al. } \\
\text { [36] } 2010(10)\end{array}$ & $385(60+)$ & $\begin{array}{c}\text { Brazil (Ermelino } \\
\text { Matarazzo) }\end{array}$ & NEWS & IPAQ L-V & $\mathrm{m}$ & 12 & 5 & 3 & 20 \\
\hline $\begin{array}{l}\text { Salvador et al. } \\
\text { [37] } 2009(11)\end{array}$ & $385(60+)$ & $\begin{array}{c}\text { Brazil (Ermelino } \\
\text { Matarazzo) }\end{array}$ & NEWS & IPAQ L-V & TRPA & 12 & 5 & 3 & 20 \\
\hline $\begin{array}{l}\text { Corseuil et al. } \\
\text { [44] } 2012 \text { (12) }\end{array}$ & $1656(60+)$ & Brazil (Florianopolis) & NEWS & IPAQ L-V & LTPA, TRPA & 11 & 4 & 3 & 18 \\
\hline $\begin{array}{l}\text { Florindo et al. } \\
\text { [41] } 2009 \text { (13) }\end{array}$ & $54369(18+)$ & Brazil (capitals cities) & Questions & Vigitel & LTPA & 10 & 5 & 3 & 18 \\
\hline $\begin{array}{l}\text { Mantilla-Toloza } \\
\text { [42] } 2006 \text { (14) }\end{array}$ & $453(15-49)$ & Colombia (Bogotá) & Questions & IPAQ L-V & LTPA & 9 & 3 & 1 & 13 \\
\hline $\begin{array}{l}\text { Rech et al. } \\
\text { [43] } 2012 \text { (15) }\end{array}$ & $1262(18-69)$ & Brazil (Curitiba) & NEWS & IPAQ L-V & $\begin{array}{l}\text { LTPA, TRPA, } \\
\text { TotalW }\end{array}$ & 12 & 5 & 4 & 21 \\
\hline
\end{tabular}

Abbreviations: NEWS Neighborhood Environment Walkability Scale; IPAQ L-V International physical activity questionnaire long version; TotalPA total physical activity; LTPA leisure-time physical activity; TRPA transport-related physical activity; TotalW total walking. IPS-EM environmental module of the International Physical Activity Prevalence Study. 
Table 2 Summary of associations between perceived environment attributes and physical activity domains by articles ID

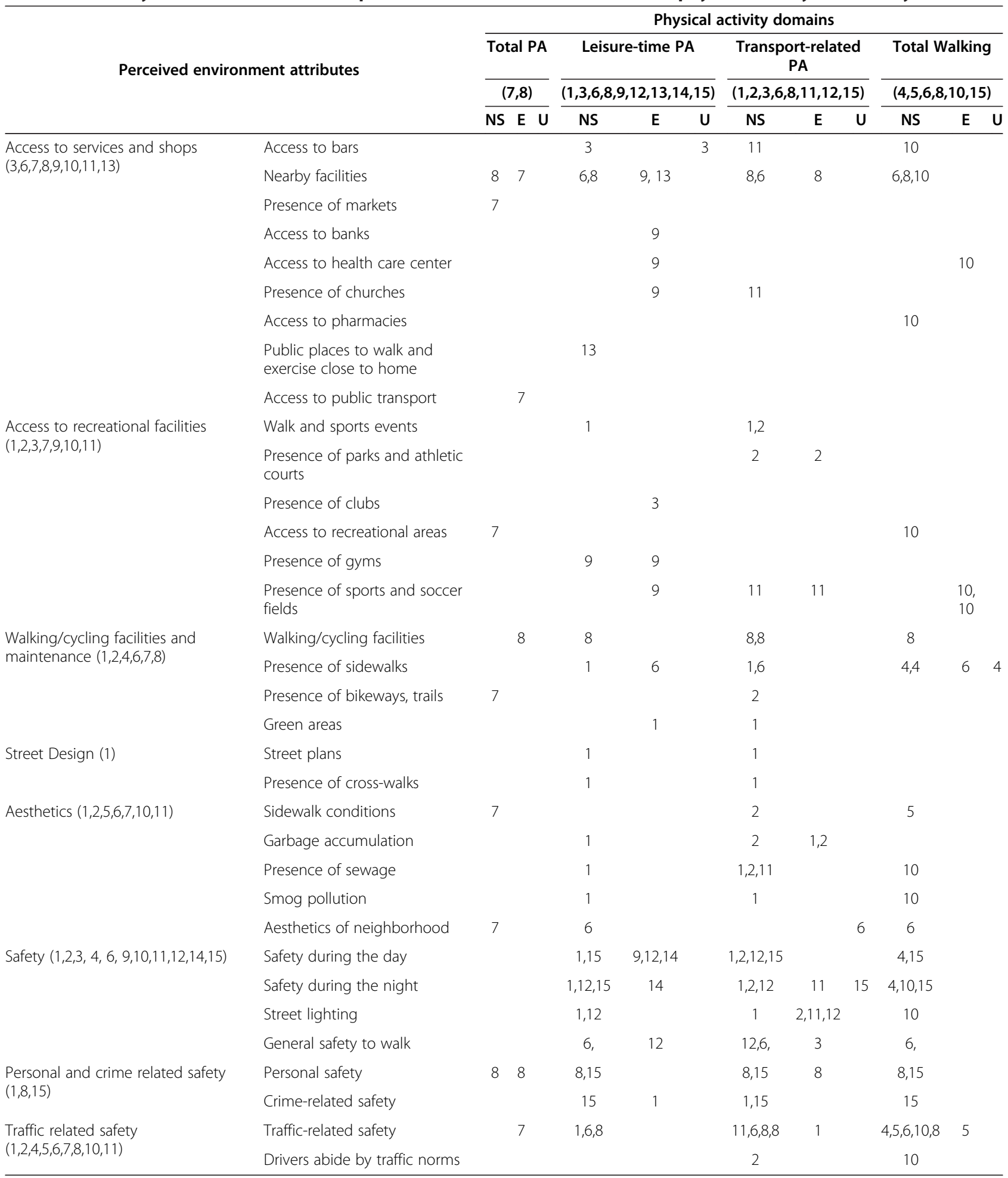

Abbreviations: NS non-significant; $E$ expected direction; $U$ unexpected direction. Numbers represent articles ID. 
Quality assessment of the studies ranged between 13 and 21 total points ( 24 points is the maximum) and the average score was 18.2 (SD 2.1). The majority of the studies $(66.7 \%)$ received $75 \%$ or more of 24 total quality points. Two of them were scored with less than $60 \%$ of the total points. None of the studies reported all items recommended by the STROBE in the methods and discussion sections. Only 6 (40\%) studies reported 5 out of 5 items in the results section.

\section{Associations of perceived environment and physical activity}

Findings of the studies reporting the adjusted associations between perceived environment attributes and physical activity domains, and the direction of these associations are summarized in Table 2. Overall, 34 of the 41 initial attributes of perceived environment were reported in the adjusted analysis of the studies. Safety from crime was the most frequently examined category of perceived environment, reported in $73.3 \%$ of the articles, followed by traffic-related safety, reported in $60 \%$ of the articles, and access to services and shops (53.3\%). The majority of associations were statistically non-significant, and only four associations were found in the unexpected direction. Leisure-time and transport-related physical activity were the domains most frequently included in the studies and had higher number of associations in the expected direction. For example, leisure-time physical activity was associated in the expected direction with safety during the day in three studies, and with nearby facilities in two studies. Also, three studies indicated associations in the expected direction between transportrelated physical activity and street lighting.

The syntheses of the associations are shown in Table 3. For leisure-time physical activity the only variable that showed a convincing association in the expected direction was safety during the day, while nearby facilities showed a suggestive association. Safety during the night and traffic-related safety were non-significant.

Transport-related physical activity had a convincing association with presence of street lighting. The presence of sewage, safety during the day, safety during the night, general safety to walk, and traffic-related safety had nonsignificant association with transport-related physical activity. For total walking, nearby facilities, safety during the night, and traffic-related safety were not significantly associated.

Associations between total physical activity and presence of sewage, safety during the day and night, street lighting, and general safety to walk were not reported in any of the studies. The remaining perceived environment elements had insufficient numbers of articles $(<3)$ preventing any evidence of association to be examined.

None of the associations were classified as contradictory results (the same number of associations in unexpected and expected directions).

\section{Discussion}

The objective of this systematic review was to analyze the current evidence of the association between perceived environment and physical activity in Latin America. The findings highlight that few perceived environment attributes have been studied, and that their association has been explored mainly in two physical activity domains (i.e. Leisure-time and transport related). Furthermore, the studies found are concentrated in only a few countries within the region, namely Brazil and Colombia. Among the examined perceived environment correlates, findings were inconsistent across physical activity domains though more consistency was found for leisure-time as compared to other domains. The only attributes presenting a convincing association with physical activity were safety from crime during the day (leisure-time) and street lightning (transport related).

Table 3 Summary of associations between perceived environment attributes and physical activity reported by 3 or more publications

\begin{tabular}{lcccc}
\hline Perceived environment attributes & Total physical activity & Leisure time physical activity & Transport-related PA & Total walking \\
\hline Nearby facilities & \multicolumn{1}{c}{ I } & + & N.S. \\
Existence of sewage & - & ++ & N.S. \\
Safety during the day & - & N.S. & N.S. \\
Safety during the night & - & I & ++ & I \\
Street lighting & - & N.S. & N.S. \\
General safety to walk & - & N.S. & N.S. \\
Traffic-related safety & I & & N.S. \\
\hline
\end{tabular}

++ : Convincing association in the expected direction.

+ : Suggestive association in the expected direction.

N.S.: non-significant associations.

I: insufficient numbers of articles.

-: Associations not studied. 
The convincing association between leisure time physical activity and safety during the day found in this study is similar from evidence gathered through systematic reviews [44,45] and meta-analysis [46] from high-income countries, where perceptions of safety seem to act as a barrier for physical activity. On the contrary for the transport related and walking domains, perceptions of personal and traffic safety were not found to be associated. This is partially explained by the fact that transport related activity represents a need rather than a choice in many countries from Latin America [16], thus is not undermined by perceptions of safety or aesthetics. However, street lighting, which could act as an indirect indicator of personal safety, reported a convincing association with transport related activity. Furthermore, the measures employed to assess safety are derived from high-income countries and they may fail to capture valuable information related to safety in Latin America. Regarding leisuretime physical activity and nearby facilities, classified as suggestive association in the expected direction, the evidence is consistent with findings from two systematic reviews on perceived environment (access to shops [46] and shops are in walking distance [47]) and physical activity. Similar findings were reported in a meta-analysis by Duncan et al. [48] in which shops and services within walking distance were associated with physical activity.

One of the main contributions from the present study is that it studies and stratifies associations according to physical activity domains, there is evidence that particular characteristics of built and perceived environments are more relevant for some domains versus others, and may also vary accordingly $[32,49,50]$. A recent systematic review found that the association between several environmental variables varied by domain, particularly between leisure-time and transport related activity, which is similar to the findings from this review [32]. Prior recommendations for the region of Latin America have suggested the use of the leisure-time and transportation sections of IPAQ as they have shown higher reliability and validity among this population [51].

Another finding of the study is that many of the highest quality studies found null associations (see Table 2). This may suggest that many of the tools and instruments used are not capturing the environmental perceptions that matter most for physical activity in Latin America. The lack of consistency on findings may be due to the small number of selected studies found in the electronic search, which indicates the lack of evidence in this area in Latin America. This area of research is relatively new in the region and only until recently have studies begun to emerge and few of them make it to the indexed literature, possibly due to lack of capacity and resources in the region [52]. Within region variability of the perceived environment context may also help to explain this inconsistency, although this is a less likely explanation, as most countries from Latin America follow similar urban designs from those of early European settlements. For instance, the higher density of Latin American cities, resulting in more proximity and accessibility to destinations, could positively influence physical activity, but the perception of personal and traffic safety hinder this association [53]. In addition, higher levels of density and connectivity usually found in Latin American cities, limits variability in study measures and the possibility of finding significant associations. The social and economic characteristics of the population from Latin America may also mediate and moderate the association between perceived environment and physical activity. It has been reported that low income populations are more likely to engage in transport related physical activity (meeting public health recommendations of at least 150 minutes per week) versus leisure time physical activity $[54,55]$. In large cities from Latin America the use of public transportation is more of a necessity rather than an option, lower rates of household car ownership (ranging between 20\% and $80 \%$ ), high prices of gas, and high accessibility to public transportation infrastructure, help explain this phenomenon. Findings may also vary by gender and according to the quality of some environmental attributes.

To our knowledge, this is the first systematic review documenting the associations between perceived environment and physical activity in Latin America and the first focusing upon findings from developing countries. The methodology used to classify and categorize the evidence has been used in similar studies, which allows establishing comparisons with other regions from the world. In addition, this approach contributes to the potential generalization of recommendations and the use of this methodology in future studies in different regions of the globe, particularly in developing countries.

Some limitations of this review need to be acknowledged. First, all 15 articles included in the review were cross-sectional studies, thus causal inference in the relationship between perceived environment and physical activity cannot be evaluated. However, the review by the US Community Guide faced the same challenge [5]. Because most of the selected studies reported only adjusted associations, the analysis was focused only on the adjusted results in order to allow consistency. This might have biased the results, however, studies adjusted their results by SES, age and education, which are common confounders in the association between perceived environment and physical activity. Prospective studies of environmental factors and physical activity are needed as well as evidence from intervention studies in order to advocate for policy changes and large-scale environmental interventions. This review has the usual limitations derived from perceptions about the environment, which may differ from objective measures, 
and is more sensitive to reporting bias. Lastly, most of the instruments used to assess perceived environment characteristics are derived from research conducted in North America, Australia and Europe and may not be sensible to key environmental features within the socio-cultural environment from Latin America. The majority of the studies were originated from Brazil followed by Colombia, with no existing evidence from other Latin American countries, in part due to the infancy of the field in Latin America $[51,52]$. However, the built environment from many Latin American countries has followed similar urbanization patterns and development as developed countries [56], and they also share common socio-cultural characteristics, making them more homogenous, which could facilitate the extrapolation of findings. A summary net effect was limited considering the wide variety of outcome measures used in the selected studies, situation that has been observed in other systematic reviews [57].

This study shows that, perceived environmental attributes and their relationship with physical activity appears to be domain, and context specific. In addition, findings from this study show inconsistencies with the information gathered from high-income countries, specifically as it relates to personal safety, while others are in accordance and can be used to advance a common agenda for the design of activity friendly environments. However, the lack of associations or the lack of studies in many of the perceived environment characteristics shows a gap in the literature. The information gathered through studies exploring perceived environment associations with physical activity can help guide the decision-making process of built environment, transportation, health and education agendas.

\section{Competing interests}

The author(s) declare that they have no competing interests.

\section{Authors' contributions}

The study was conceived by CA, DC-Pa, and RB. Articles search and data extractions were made by CA and DC-Pz. Quality assessment by CA, DC-Pz, and $R R . R B, R R$ and DC-Pa reviewed the article critically for important intellectual content. All authors were involved in writing the paper and had final approval of the submitted and published versions.

\section{Acknowledgments}

This study was supported in part by Cooperative Agreement Number U48/ DP001903 from the Centers for Disease Control and Prevention (the Prevention Research Centers Program).

\section{Author details}

'Prevention Research Center in St. Louis, Brown School, Washington University in St. Louis, 660 S. Euclid Ave, St. Louis, Missouri MO 63110, USA. ${ }^{2}$ Department of Health, Leisure and Exercise Science, University of West Florida, 11000 University Parkway, 32514, Pensacola, Florida, USA. ${ }^{3}$ School of Health and Biosciences, Pontifícia Universidade Católica do Paraná, Rua Imaculada Conceição, 1155 - Prado Velho, Curitiba-PR 80215-901, Brazil. ${ }^{4}$ Department of Physical Education, Federal University of Parana, Rua Coracao de Maria 92 - Jardim Botânico, Curitiba - PR 80210-132, Brazil. ${ }^{5}$ Division of Public Health Sciences and Alvin J. Siteman Cancer Center, Washington University School of Medicine, Washington University in St. Louis, 660 S. Euclid Ave, St. Louis, MO 63110, USA.
Received: 17 December 2012 Accepted: 28 October 2013

Published: 31 October 2013

\section{References}

1. Barreto SM, Miranda JJ, Figueroa JP, Schmidt MI, Munoz S, Kuri-Morales PP, Silva JB Jr: Epidemiology in Latin America and the Caribbean: current situation and challenges. Int J Epidemiol 2012, 41:557-571.

2. Jacoby E, Bull F, Neiman A: Rapid changes in lifestyle make increased physical activity a priority for the americas. Rev Panam Salud Publica 2003, 14(223-225):226-228.

3. ONU-Habitat: Estado de las ciudades de américa latina y el caribe, 2012 Rumbo a una nueva transición urbana. Brasil: ONU-Habitat; 2012.

4. Hallal PC, Andersen LB, Bull FC, Guthold R, Haskell W, Ekelund U: Global physical activity levels: surveillance progress, pitfalls, and prospects. Lancet 2012, 380:247-257.

5. Heath G, Brownson R, Kruger J, Miles R, Powell K, Ramsey L: The effectiveness of urban design and land use and transport policies and practices to increase physical activity: a systematic review. J Phys Act Health 2006, 3 (Suppl 1):S55-S76.

6. Brownson RC, Kelly CM, Eyler AA, Carnoske C, Grost L, Handy SL, Maddock JE, Pluto D, Ritacco BA, Sallis JF, Schmid TL: Environmental and policy approaches for promoting physical activity in the united states: a research agenda. J Phys Act Health 2008, 5:488-503.

7. Heath GW, Parra DC, Sarmiento OL, Andersen LB, Owen N, Goenka S, Montes F, Brownson RC: Evidence-based intervention in physical activity: lessons from around the world. Lancet 2012, 380:272-281.

8. World Health Organization: Global Strategy on Diet, Physical Activity and Health. Geneva, Switzerland: World Health Organization; 2004.

9. Owen N, Humpel N, Leslie E, Bauman A, Sallis JF: Understanding environmental influences on walking; review and research agenda. Am J Prev Med 2004, 27:67-76.

10. Bauman AE, Reis RS, Sallis JF, Wells JC, Loos RJ, Martin BW: Correlates of physical activity: Why are some people physically active and others not? Lancet 2012, 380:258-271.

11. Parra DC, Hoehner CM, Hallal PC, Ribeiro IC, Reis R, Brownson RC, Pratt M, Simoes EJ: Perceived environmental correlates of physical activity for leisure and transportation in Curitiba, Brazil. Prev Med 2011, 52:234-238.

12. Bourguignon FJ: Crime as a social cost of poverty and inequality: a review focusing on developing countries. Revista Desarrollo y Sociedad; 2009:61-99.

13. Gomes GA, Reis RS, Parra DC, Ribeiro I, Hino AA, Hallal PC, Malta DC, Brownson RC: Walking for leisure among adults from three Brazilian Cities and its association with perceived environment attributes and personal factors. Int J Behav Nutr Phys Act 2011, 8:111.

14. Gómez LF, Parra DC, Buchner D, Brownson RC, Sarmiento OL, Pinzón JD, Ardila M, Moreno J, Serrato M, Lobelo F: Built environment attributes and walking patterns among the elderly population in Bogotá. Am J Prev Med 2010, 38:592-599.

15. Comaru Fde A, Westphal MF: Housing, urban development and health in Latin America: contrasts, inequalities and challenges. Rev Environ Health 2004, 19:329-345.

16. Becerra JM, Reis RS, Frank LD, Ramirez-Marrero FA, Welle B, Arriaga Cordero E, Mendez Paz F, Crespo C, Dujon V, Jacoby E, Dill J, Weigand L, Padin CM: Transport and health: a look at three Latin American cities. Cad Saude Publica 2013, 29:654-666.

17. Martine G: The New Global Frontier: Urbanization, Poverty and Environment in the 21st Century. London: Earthscan; 2008.

18. Cerin E, Conway TL, Cain KL, Kerr J, De Bourdeaudhuij I, Owen N, Reis RS, Sarmiento OL, Hinckson EA, Salvo D, Christiansen LB, Macfarlane DJ, Davey R, Mitas J, Aguinaga-Ontoso I, Sallis JF: Sharing good news across the world: Developing comparable scores across 12 countries for the neighborhood environment walkability scale (news). BMC Public Health 2013, 13:309.

19. Doyle J, Waters E, Yach D, McQueen D, De Francisco A, Stewart T, Reddy P, Gulmezoglu AM, Galea G, Portela A: Global priority setting for cochrane systematic reviews of health promotion and public health research. J Epidemiol Community Health 2005, 59:193-197.

20. Reis RS, Kelly CM, Parra DC, Barros M, Gomes G, Malta D, Schmid T, Brownson RC: Developing a research agenda for promoting physical activity in brazil through environmental and policy change. Rev Panam Salud Publica 2012, 32:93-100. 
21. Moher D, Liberati A, Tetzlaff J, Altman DG: Preferred reporting items for systematic reviews and meta-analyses: the prisma statement. Ann Intern Med 2009, 151:264-269. W264.

22. United Nations: Composition of Macro Geographical (Continental) Regions, Geographical Sub-Regions, and Selected Economic and Other Groupings. United Nations Statistics Division; 2011. Revised 20 September 2011. [http://unstats.un.org/unsd/methods/m49/m49regin.htm].

23. Saelens BE, Sallis JF, Black JB, Chen D: Neighborhood-based differences in physical activity: an environment scale evaluation. Am J Public Health 2003, 93:1552-1558.

24. Brownson RC, Hoehner CM, Day K, Forsyth A, Sallis JF: Measuring the built environment for physical activity: State of the science. Am J Prev Med 2009, 36:S99-S123. e112.

25. Eisenstein AR, Prohaska TR, Kruger J, Satariano WA, Hooker S, Buchner D, Kealey M, Hunter RH: Environmental correlates of overweight and obesity in community residing older adults. J Aging Health 2011, 23:994-1009.

26. Kaczynski AT: Neighborhood walkability perceptions: Associations with amount of neighborhood-based physical activity by intensity and purpose. J Phys Act Health 2010, 7:3-10.

27. Van Dyck D, Cardon G, Deforche B, De Bourdeaudhuij I: Lower neighbourhood walkability and longer distance to school are related to physical activity in belgian adolescents. Prev Med 2009, 48:516-518.

28. Gebel K, Bauman AE, Sugiyama T, Owen N: Mismatch between perceived and objectively assessed neighborhood walkability attributes: prospective relationships with walking and weight gain. Health Place 2011, 17:519-524.

29. Murayama H, Yoshie S, Sugawara I, Wakui T, Arami R: Contextual effect of neighborhood environment on homebound elderly in a japanese community. Arch Gerontol Geriatr 2012, 54:67-71.

30. Florindo AA, Salvador EP, Reis RS, Guimarães W: Percepção do ambiente e prática de atividade física em adultos residentes em região de baixo nível socioeconômico. Rev Saude Publica 2011, 45:302-310.

31. Pont K, Ziviani J, Wadley D, Bennett S, Abbott R: Environmental correlates of children's active transportation: a systematic literature review. Health Place 2009, 15:827-840.

32. Van Holle V, Deforche B, Van Cauwenberg J, Goubert L, Maes L, Van de Weghe N, De Bourdeaudhuij I: Relationship between the physical environment and different domains of physical activity in European adults: a systematic review. BMC Public Health 2012, 12:807.

33. von Elm E, Altman DG, Egger M, Pocock SJ, Gotzsche PC, Vandenbroucke JP: The strengthening the reporting of observational studies in epidemiology (strobe) statement: guidelines for reporting observational studies. Lancet 2007, 370:1453-1457.

34. Corseuil MW, Schneider IJ, Silva DA, Costa FF, Silva KS, Borges LJ, d'Orsi E: Perception of environmental obstacles to commuting physical activity in brazilian elderly. Prev Med 2011, 53:289-292.

35. Salvador EP, Florindo AA, Reis RS, Costa EF: Percepção do ambiente e prática de atividade física no lazer entre idosos. Rev Saude Publica 2009, 43:972-980.

36. Salvador EP, Reis RS, Florindo AA: Practice of walking and its association with perceived environment among elderly brazilians living in a region of low socioeconomic level. Int J Behav Nutr Phys Act 2010, 7:67.

37. Salvador EP, Reis RS, Florindo AA: A prática de caminhada como forma de deslocamento e sua associação com a percepção do ambiente em idosos. Rev bras ativ fís saúde 2009, 14:197-205.

38. Amorim TC, Azevedo MR, Hallal PC: Physical activity levels according to physical and social environmental factors in a sample of adults living in South Brazil. J Phys Act Health 2010, 7(Suppl 2):S204-S212.

39. Hallal PC, Reis RS, Parra DC, Hoehner C, Brownson RC, Simões EJ: Association between perceived environmental attributes and physical activity among adults in Recife, Brazil. J Phys Act Health 2010, 7(Suppl 2):S213-S222.

40. Herazo-Beltrán Y, Domínguez-Anaya R: Percepción del ambiente y niveles de actividad física en adultos de un Barrio de Cartagena. Rev Salud Publica (Bogota) 2010, 12:744-753.

41. Florindo AA, Hallal PC, Moura EC, Malta DC: Practice of physical activities and associated factors in adults, Brazil, 2006. Rev Saude Publica 2009, 43(Suppl 2):65-73.

42. Mantilla-Toloza SC: physical activity in people aged 15 to 49 living in a particular locality in Bogota, Colombia, 2004. Rev Salud Publica 2006, 8(2):69-80.
43. Rech CR, Reis RS, Hino AA, Rodriguez-Anez CR, Fermino RC, Goncalves PB, Hallal PC: Neighborhood safety and physical inactivity in adults from Curitiba, Brazil. Int J Behav Nutr Phys Act 2012, 9:72.

44. Corseuil MW, Hallal PC, Corseuil HX, Schneider IJ, d'Orsi E: Safety from crime and physical activity among older adults: a population-based study in Brazil. J Environ Public Health 2012, 2012:7.

45. Craig CL, Marshall AL, Sjostrom M, Bauman AE, Booth ML, Ainsworth BE, Pratt $M$, Ekelund U, Yngve A, Sallis JF, Oja P: International physical activity questionnaire: 12-country reliability and validity. Med Sci Sports Exerc 2003, 35:1381-1395.

46. Van Cauwenberg J, De Bourdeaudhuij I, De Meester F, Van Dyck D, Salmon J, Clarys P, Deforche B: Relationship between the physical environment and physical activity in older adults: A systematic review. Health Place 2011, 17:458-469.

47. Humpel N, Owen N, Leslie E: Environmental factors associated with adults' participation in physical activity: a review. Am J Prev Med 2002, 22:188-199.

48. Duncan MJ, Spence JC, Mummery WK: Perceived environment and physical activity: a meta-analysis of selected environmental characteristics. Int J Behav Nutr Phys Act 2005, 2:11

49. Saelens BE, Handy SL: Built environment correlates of walking: a review. Med Sci Sports Exerc 2008, 40:S550-S566

50. Sallis JF, Cervero RB, Ascher W, Henderson KA, Kraft MK, Kerr J: An ecological approach to creating active living communities. Annu Rev Public Health 2006, 27:297-322.

51. Hallal PC, Gomez LF, Parra DC, Lobelo F, Mosquera J, Florindo AA, Reis RS, Pratt M, Sarmiento OL: Lessons learned after 10 years of ipaq use in Brazil and Colombia. J Phys Act Health 2010, 7(Suppl 2):S259-S264.

52. Hallal PC, Parra DC, Azevedo MR, Pratt M, Brownson RC: Research on physical activity and health: Where is latin america? J Phys Act Health 2010, 7(Suppl 2):S129-S130.

53. McGinn AP, Evenson KR, Herring AH, Huston SL, Rodriguez DA: Exploring associations between physical activity and perceived and objective measures of the built environment. J Urban Health 2007, 84:162-184.

54. Pucher J, Renne J: Socioeconomics of urban travel: evidence from the 2001 nhts. Transp Quart 2003, 57:49-77.

55. Sánchez TW, Stolz R, Ma JS: Moving to Equity: Addressing Inequitable Effects of Transportation Policies on Minorities. Cambridge, MA: The Civil Rights Project at Harvard University; 2003.

56. Knox PL, McCarthy L: Urbanization: An Introduction to Urban Geography. 3rd edition. Boston: Pearson; 2012.

57. Kahn EB, Ramsey LT, Brownson RC, Heath GW, Howze EH, Powell KE, Stone EJ, Rajab MW, Corso P: The effectiveness of interventions to increase physical activity. A systematic review. Am J Prev Med 2002, 22:73-107.

doi:10.1186/1479-5868-10-122

Cite this article as: Arango et al:: Association between the perceived environment and physical activity among adults in Latin America: a systematic review. International Journal of Behavioral Nutrition and Physical Activity 2013 10:122.

\section{Submit your next manuscript to BioMed Central and take full advantage of:}

- Convenient online submission

- Thorough peer review

- No space constraints or color figure charges

- Immediate publication on acceptance

- Inclusion in PubMed, CAS, Scopus and Google Scholar

- Research which is freely available for redistribution 